\title{
Age-related differences in the prehospital management of 2,500 patients with sudden cardiac arrest
}

Janusz Sielski ${ }^{1}$, Karol Kaziród-Wolski ${ }^{1}$, Marta Solnica ${ }^{2}$, Mirosław Data ${ }^{1}$, Dominika Kukla ${ }^{1}$, Kamil Woźnica ${ }^{1}$, Marcin Sadowski ${ }^{1}$

\author{
${ }^{1}$ Institute of Medical Sciences,, Collegium Medicum, The Jan Kochanowski University, \\ Kielce, Poland \\ ${ }^{2}$ The Świętokrzyskie Centre for Medical Emergency and Transport Services, Kielce, \\ Poland
}

Submitted: 5 November 2020

Accepted: 17 March 2021

Arch Med Sci

DOI: https://doi.org/10.5114/aoms/134614

Copyright $\odot 2021$ Termedia \& Banach

\section{Abstract}

Introduction: Prehospital care affects outcomes after out-of-hospital cardiac arrest (OHCA). The aim of the study is to analyze age-related differences in prehospital care and survival after OHCA and to define variables affecting the efficacy of cardiopulmonary resuscitation (CPR).

Material and methods: We performed analysis of differences in patient characteristics influencing the efficacy of CPR and analysis of survival in four age groups: $<65,65-74,75-84$, and $\geq 85$. This retrospective registry-based study aimed to compare prehospital care in OHCA patients across age groups.

Results: CPR was performed in 2,500 patients. Return of spontaneous circulation (ROSC) occurred in 1061 subjects. Of them, 339 had incomplete medical records, 201 survived at least 24 h, 115 up to 30 days and 78 were alive at 365 days after discharge. The occurrence of shockable rhythms and the ROSC rate decreased with age. Overall mortality increased with age. Such factors as age, gender, urban area, home location, time to arrival, and witnessed OHCA were predictors of the initial shockable rhythm. Gender, urban area, OHCA witnessed by family member, time to arrival, cardiac cause and shockable rhythm were predictors of ROSC. The risk of death increased with each age group by about $56 \%(H R=1.56, p<0.0001)$.

Conclusions: Shockable initial rhythm and urban location were the strongest predictors of ROSC. Survival at 30 and 365 days after OHCA decreased in older patients. Survival among older patients with OHCA is worse than in younger subjects, which results from lower efficacy of resuscitation and more frequent death declared upon arrival.

Key words: resuscitation, sudden cardiac death, out-of-hospital cardiac arrest, prehospital care, return of spontaneous circulation.

\section{Introduction}

The origins of cardiopulmonary resuscitation (CPR) date back to the 1950s. Since that time the procedure introduced in patients with out-of-hospital cardiac arrest (OHCA) has evolved with technology [1]. However, OHCA is still one of the leading causes of global death in subjects over 40 years of age [2, 3]. OHCA in Europe occurs with a frequency of 350,000-700,000 (mean: 500,000) events per year, which gives an

\author{
Corresponding author: \\ Karol Kaziród-Wolski \\ Collegium Medicum \\ Jan Kochanowski University \\ Kielce, Poland \\ Phone: +48 413671493 \\ E-mail: karol.kazirod-wolski@ \\ ujk.edu.pl
}


average of $55-113$ per 100,000 inhabitants [4] In 2016 in Poland, among approximately 388,000 deaths (202,000 men (52.1\%) and 186,000 women $(47.9 \%)), 43.7 \%$ of them were due to cardiovascular causes, mainly cardiac $(60.6 \%)$ followed by cerebrovascular disease $(17.3 \%)[5,6]$. The proportion of OHCA survivors discharged from hospitals ranges from 0 to $20 \%$ and has not changed for almost 30 years [7]. Importantly, aging is associated with a concomitant increase in OHCA incidence. Adults aged 70 years and older also have worse prognosis and the proportion of those discharged home is only $4.1 \%$ [8]. By 2050 , low- and middle-income countries are estimated to have $80 \%$ of their populations aged 60 years or older, whereas $25 \%$ of Europe's population will be 65 years old or older [7]. According to estimates, over a quarter of the Polish population will be 65 years old or older by 2050 , and by 2060 , Poland will be considered one of the oldest societies in the European Union [9]. Poland's population has been declining in recent years. In 2017, there were $38,422,346$ people (51.6\% female) [10].

According to the forecasts, by 2050 the population of Poland will have decreased by $4,487,000$ $(11.7 \%)$ to $33,951,000$ people. The strongest depopulation processes will occur in urban areas. Towns and cities will lose $18.7 \%$ of the population as compared with $1 \%$ in rural areas. Swietokrzyskie District will also experience the process of urban shrinkage. The population decline is expected to be $22.3 \%$. This implies a faster rate of depopulation in Swietokrzyskie District than the average in Poland. In 2015 Swietokrzyskie District accounted for $3.3 \%$ of the population in the country, but this is predicted to decrease significantly to $2.9 \%$ by 2050 [11].

The first electrocardiogram recordings define qualification to typical cardiac procedures and pharmacotherapy, such as urgent coronary angiography and invasive treatment of coronary artery disease [12]. Data regarding out-of-hospital cardiac arrest have been obtained from several registries. One of them is the National Registry of Invasive Cardiology Procedures (ORPKI) [13]. In 2018, a national registry of OHCA was launched, which will replace regional registries and will become an excellent source of information regarding OHCA cases.

A variety of factors affect survival after an OHCA. Of them, the most important is the role of OHCA witnesses, bystander-performed CPR, and the role of emergency medical dispatchers. Age of the patient is less important $[14,15]$. There are also programs for specialist treatment of patients at the scene. One such program is "ECMO for Greater Poland" promoting ECMO therapy in patients with OHCA [16].

\section{Material and methods}

In 2016, the medical team of the Intensive Coronary Care Unit at Świętokrzyskie Cardiology Centre, Regional Hospital in Kielce in cooperation with the medical and nursing team of the Świętokrzyskie Centre for Medical Emergency and Transport Services in Kielce launched a data registry for patients with cardiac arrest that occurred outside of a hospital setting. Preliminary analysis of the data collected in 2013-2016 together with a description of the study group and implications for prehospital care of OHCA patients have been published elsewhere. The present study is a retrospective registry for the period between 1 January 2013 and 31 December 2017. We analyzed the occurrence of OHCA in Świętokrzyskie District according to data published by Statistics Poland. Prehospital care information was obtained from medical documentation. Patients were selected from a population of subjects who had been evaluated by medical rescuers/physicians. Patients diagnosed with sudden cardiac arrest were candidates for the study. Early recognition of OHCA by the dispatcher was confirmed by emergency medical service (EMS) upon arrival. Data regarding the activity of Medical Rescue Teams were extracted from two types of records: 1. emergency rescue card orders, and 2 . medical rescue procedure charts. Those who experienced an OHCA and achieved return of spontaneous circulation (ROSC) entered the study. Survival was determined based on the National Health Fund statistics regarding hospital admissions, hospital stays and deaths. Further steps in the process of patient selection are depicted in Figure 1. We evaluated all variables provided by EMS crews. An OHCA of cardiac etiology was defined as an event occurring in the presence of clinical and electrocardiographic symptoms of acute coronary syndromes or signs of heart failure or a shockable initial rhythm. Patients were divided into four-age groups: $<65,65-$ $74,75-84$ and patients aged 85 years and over. The study was approved by the Research Ethics Committee of the Faculty of Medicine and Health Sciences at Jan Kochanowski University in Kielce (Resolution no. 48/2016 of 9 December 2016).

\section{Statistical analysis}

Descriptive statistics were used to present data collected over a 5-year period. Categorical variables are presented as counts and percentages. The Shapiro-Wilk test and Kolmogorov-Smirnov test were used to test for normality of distribution. Because of non-normal distribution quantitative variables are expressed as median and interquartile range, and the non-parametric Kruskal-Wallis test was used for comparing differences in quantitative 
variables. Cross tabulation with the $\chi^{2}$ test and the $\chi^{2}$ test for trend were used for testing relationships between categorical variables. Univariate and multivariable logistic regression analysis was performed to estimate the odds ratio (OR) and $95 \%$ confidence interval $(95 \% \mathrm{Cl})$ in search of factors influencing the occurrence of OHCA with cardiac etiology, shockable initial rhythm and ROSC. Goodness of fit in multivariable regression logistic models was measured using area under the curve (AUC) statistic. The Kaplan-Meier survival curve and the Cox proportional hazards regression analysis model were used to estimate the probability of survival. Survival analysis was performed for patients who survived the first day of hospitalization. MedCalc Statistical Software version 19.1 (MedCalc Software, Ostend, Belgium) was used to perform statistical analyses [17].

\section{Results}

Between 2013 and 2017 there were 3,363 cases of OHCA. Of them, 53 cases with incomplete medical records and 8 pediatric OHCA patients were further excluded from the analysis. A total of 802 patients were found dead prior to admission to the hospital, and CPR was attempted by the attending ambulance crew in 2,500 patients. Initial CPR was unsuccessful in 1,439 patients, whereas ROSC occurred in 1,061 subjects. In the ROSC group medical records were incomplete in 339 patients and excluded from further analysis. Of 722 patients, 201 (28\%) survived at least $24 \mathrm{~h}$, $115(16 \%)$ up to 30 days and 78 (11\%) were alive at 365 days after discharge (Figure 1$)$.

Table I summarizes baseline patient characteristics. The predominance of women was observed only in the oldest age group. In patients 65-74 years old time to arrival at the scene was shortest, and OHCA most frequently occurred in urban area. In each age group the OHCA rate was higher in rural compared to urban areas. OHCA occurred mainly at home and was witnessed by family members. Fewer patients were found dead upon arrival at the scene and CPR was attempted in most cases. Across four consecutive age groups OHCA was increasingly more frequent in rural areas. The number of patients found dead upon arrival increased only among those over 75 years of age. The population of Świętokrzyskie District was graphically represented as an age-gender-pyramid (Figure 2). Table II summarizes baseline characteristics of the patients who experienced CPR attempts. There were no differences in time to arrival at the scene, the number of witnesses and transport destination after resuscitation (intensive coronary care unit (ICCU) vs. emergency departments (ED)). In most groups there were more men than women, but the proportions gradually reversed and the oldest

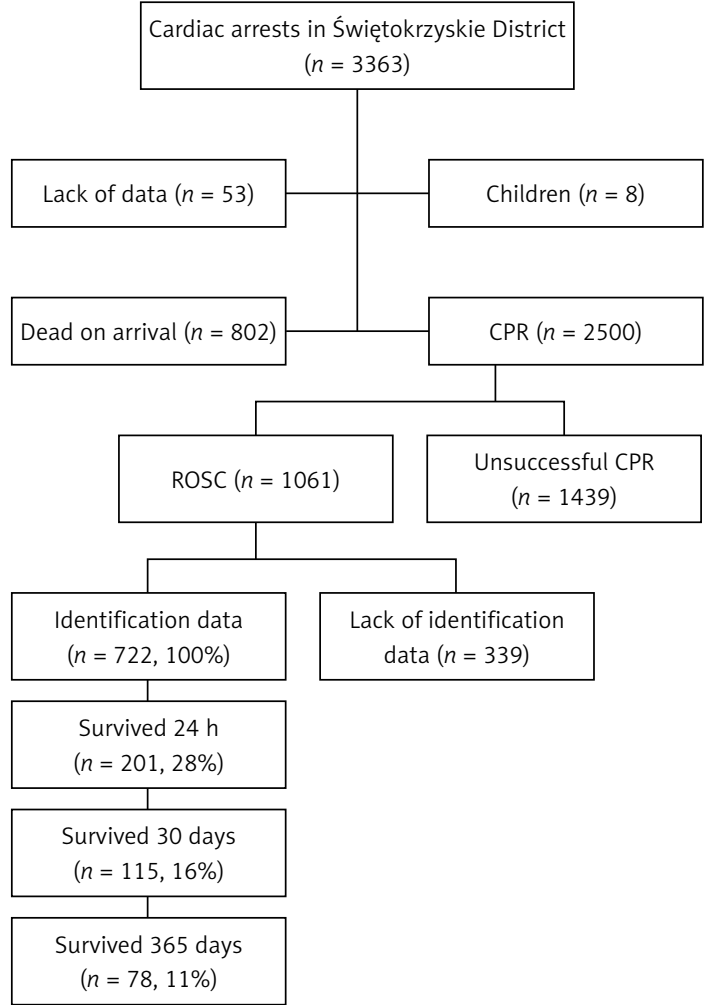

Figure 1. Study patient flow chart. CPR, cardiopulmonary resuscitation. OHCA, out-of-hospital cardiac arrest

group was predominantly female. With increasing age CPR was more frequently attempted in the patient's home, in rural areas, and emergency calls were mainly made by family members. Among patients with CPR attempts the number of witnesses and the rate of ambulance transport to an ICCU were similar in each age group. Only the youngest patients more frequently experienced OHCA of non-cardiac etiology. The incidence of OHCA events of cardiac origin increased with age and was prevalent in the remaining three groups. In general, a shockable initial rhythm was less frequently found than the non-shockable rhythm, and the occurrence of shockable rhythms decreased with age. The rate of ROSC decreased with age, with the most remarkable drop among the oldest patients. Overall mortality, defined as the sum of patients dead on arrival and following unsuccessful CPR, increased with age. Multivariable logistic regression analysis demonstrated that age, male sex, OHCA witnessed by family member, and citizen-witnessed OHCA were independent predictors of OHCA of cardiac etiology. Age, male sex, urban area, home location, time to arrival, and witnessed OHCA independently predicted the initial shockable rhythm. Return of spontaneous circulation was best predicted by female sex, urban area, family-witnessed OHCA, time to arrival, cardiac etiology and the presence of a shockable initial rhythm (Table III). Receiver operating characteristic curves are shown in Figure 3. 
Janusz Sielski, Karol Kaziród-Wolski, Marta Solnica, Mirosław Data, Dominika Kukla, Kamil Woźnica, Marcin Sadowski

Table I. Baseline characteristics of patients with out-of-hospital cardiac arrest between 2013 and 2017

\begin{tabular}{|c|c|c|c|c|c|c|}
\hline \multirow[t]{2}{*}{ Variable } & \multicolumn{4}{|c|}{ Age groups [years] } & \multicolumn{2}{|c|}{$P$-value } \\
\hline & $<65$ & $65-74$ & $75-84$ & $\geq 85$ & $\begin{array}{c}\text { Between } \\
\text { groups }\end{array}$ & For trend \\
\hline Number & 1385 (41.9) & $717(21.7)$ & $709(21.5)$ & $491(14.9)$ & $<0.001$ & NA \\
\hline $\begin{array}{l}\text { Age [years] } \\
\text { median }(\mathrm{IQR})^{\star}\end{array}$ & $57(50-61)$ & $69(67-72)$ & $80(77-82)$ & $88(86-91)$ & $<0.001$ & NA \\
\hline $\begin{array}{l}\text { Time to arrival } \\
{[\mathrm{min}] \text { median }} \\
(\mathrm{IQR})^{\star}\end{array}$ & $10(6-15)$ & $9(6-14)$ & $10(6-15)$ & $10(6-15)$ & 0.03 & NA \\
\hline \multicolumn{7}{|l|}{ Sex ${ }^{*}$} \\
\hline Male & $1082(78.1)$ & $478(66.7)$ & $396(55.9)$ & $193(39.3)$ & \multirow[t]{2}{*}{$<0.001$} & \multirow[t]{2}{*}{$<0.001$} \\
\hline Female & $303(21.9)$ & $239(33.3)$ & $313(44.1)$ & $298(60.7)$ & & \\
\hline \multicolumn{7}{|l|}{ Area: } \\
\hline Urban & $470(33.9)$ & $281(39.2)$ & $236(33.3)$ & $146(29.7)$ & \multirow[t]{2}{*}{0.006} & \multirow[t]{2}{*}{$<0.001$} \\
\hline Rural & $915(66.1)$ & $436(60.8)$ & $473(66.7)$ & $345(70.3)$ & & \\
\hline \multicolumn{7}{|l|}{ Location*: } \\
\hline Home & $990(71.5)$ & $571(79.6)$ & $598(84.3)$ & $444(90.4)$ & \multirow[t]{2}{*}{$<0.001$} & \multirow[t]{2}{*}{$<0.001$} \\
\hline Others & $395(28.5)$ & $146(20.4)$ & $111(15.7)$ & $47(9.6)$ & & \\
\hline \multicolumn{7}{|l|}{ Eye-witness: } \\
\hline Family & $984(71.1)$ & $567(79.1)$ & $612(86.3)$ & $435(88.6)$ & \multirow[t]{2}{*}{$<0.001$} & \multirow[t]{2}{*}{$<0.001$} \\
\hline Other & $400(28.9)$ & $150(20.9)$ & $97(13.7)$ & $56(11.4)$ & & \\
\hline \multicolumn{7}{|l|}{ Dead on arrival: } \\
\hline Yes & $297(21.4)$ & $145(20.2)$ & $175(24.7)$ & $185(37.7)$ & \multirow[t]{2}{*}{$<0.001$} & \multirow[t]{2}{*}{$<0.001$} \\
\hline No & $1088(78.7)$ & $572(79.8)$ & $534(75.3)$ & $306(62.3)$ & & \\
\hline
\end{tabular}

Data are presented as number and percentages unless otherwise indicated; NA - not applicable; ${ }^{*}$ ata presented according to Utstein criteria.

All models were statistically significant and well fitted the set of data. The highest area under the curve values were found for models accounting for the presence of shockable initial rhythm and ROSC achievement. There was a significant difference in survival in the consecutive age ranges, with the

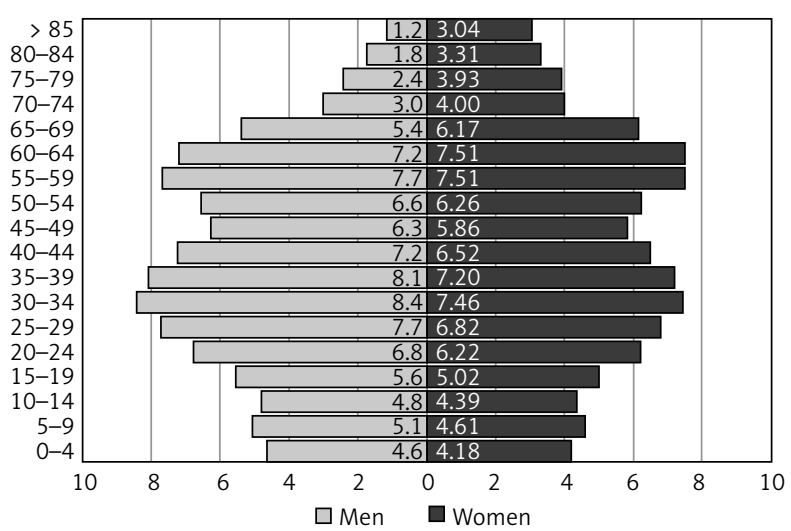

Figure 2. Świętokrzyskie District population age-gender-pyramid shortest survival in the oldest patients and the longest one in the youngest subjects (Figure 4). Proportions of OHCA survivors and hazard ratios in each age group were also calculated at 30 days and 365 days after the index event (Table IV). The risk of death increased with each age group by about $56 \%$ $(\mathrm{HR}=1.56, p<0.0001)$.

\section{Discussion}

The present analysis concerns Świętokrzyskie District, which covers an area of $11,710 \mathrm{~km}^{2}$. In 2017 , our district had 127,147 people aged $65-74$ (55.7\% female), 70,224 people aged 75-84 (64.2\% female) and 28,482 people aged 85 years and over (72.6\% female) [10]. In recent years there has been a remarkable demographic decline accompanied by population aging in the district. Between 2013 and 2016 the number of citizens decreased by 21,095 people ( $45.8 \%$ female) [10]. In line with the depopulation trend in the district, the emergency medical services system underwent major organizational changes. 
Table II. Baseline characteristics of patients who underwent cardiopulmonary resuscitation between 2013 and 2017

\begin{tabular}{|c|c|c|c|c|c|c|}
\hline \multirow[t]{2}{*}{ Variable } & \multicolumn{4}{|c|}{ Age groups [years] } & \multicolumn{2}{|c|}{$P$-value } \\
\hline & $<65$ & $65-74$ & $75-84$ & $\geq 85$ & $\begin{array}{l}\text { Between } \\
\text { groups }\end{array}$ & For trend \\
\hline Number & $1088(43.5)$ & $572(22.9)$ & $534(21.4)$ & $306(12.2)$ & $<0.001$ & NA \\
\hline $\begin{array}{l}\text { Age [years] } \\
\text { median }(\mathrm{IQR})^{*}\end{array}$ & $57(50-61)$ & $69(66-72)$ & $80(77-82)$ & $88(86-90)$ & $<0.001$ & NA \\
\hline $\begin{array}{l}\text { Time to arrival } \\
{[\mathrm{min}] \text { median, }} \\
(\mathrm{IQR})^{\star}:\end{array}$ & $10(6-15)$ & $9(6-14)$ & $10(6-15)$ & $10(6-14)$ & 0.15 & NA \\
\hline \multicolumn{7}{|l|}{ Sex*: } \\
\hline Male & $843(77.5)$ & $380(66.4)$ & $296(55.4)$ & $122(39.9)$ & \multirow[t]{2}{*}{$<0.001$} & \multirow[t]{2}{*}{$<0.001$} \\
\hline Female & $245(22.5)$ & $192(33.6)$ & $238(44.6)$ & $245(22.5)$ & & \\
\hline \multicolumn{7}{|l|}{ Location*: } \\
\hline Home & $740(68.0)$ & $445(77.8)$ & $442(82.8)$ & $273(89.2)$ & \multirow[t]{2}{*}{$<0.001$} & \multirow[t]{2}{*}{$<0.001$} \\
\hline Others & $348(32.0)$ & $127(22.2)$ & $92(17.2)$ & $33(10.8)$ & & \\
\hline \multicolumn{7}{|l|}{ Eye-witness: } \\
\hline Family & $745(68.5)$ & $440(76.9)$ & $451(84.5)$ & $260(85.0)$ & \multirow[t]{2}{*}{$<0.001$} & \multirow[t]{2}{*}{$<0.001$} \\
\hline Other & $342(31.5)$ & $132(23.1)$ & $83(15.5)$ & $46(15.0)$ & & \\
\hline \multicolumn{7}{|l|}{ Area: } \\
\hline Urban & $395(36.3)$ & $233(40.7)$ & $190(35.6)$ & $87(28.4)$ & \multirow[t]{2}{*}{0.004} & \multirow[t]{2}{*}{0.04} \\
\hline Rural & $693(63.7)$ & $339(59.3)$ & $344(64.4)$ & $219(71.6)$ & & \\
\hline \multicolumn{7}{|c|}{ Witnesses (bystander CPR)*: } \\
\hline Yes & $355(32.6)$ & $193(33.7)$ & $147(27.5)$ & $89(29.1)$ & \multirow[t]{2}{*}{0.08} & \multirow[t]{2}{*}{0.05} \\
\hline No & $733(67.4)$ & $379(66.3)$ & $387(66.3)$ & $217(70.9)$ & & \\
\hline \multicolumn{7}{|c|}{ Cause of OHCA*: } \\
\hline Cardiac & $506(46.5)$ & $325(56.8)$ & $337(63.1)$ & $188(61.5)$ & \multirow[t]{2}{*}{$<0.001$} & \multirow[t]{2}{*}{$<0.001$} \\
\hline Others & $582(53.5)$ & $247(43.2)$ & $197(36.9)$ & $118(38.6)$ & & \\
\hline \multicolumn{7}{|l|}{ Heart rhythm*: } \\
\hline VT/VF & $219(20.1)$ & $98(17.1)$ & $69(12.9)$ & $24(7.8)$ & \multirow[t]{2}{*}{$<0.001$} & \multirow[t]{2}{*}{$<0.001$} \\
\hline Other & $869(79.9)$ & $474(82.9)$ & $465(87.1)$ & $282(92.2)$ & & \\
\hline \multicolumn{7}{|l|}{ Transport*: } \\
\hline ICCU & $31(6.5)$ & $19(7.4)$ & $13(5.9)$ & $3(2.8)$ & \multirow[t]{2}{*}{0.43} & \multirow[t]{2}{*}{0.26} \\
\hline ED & $447(93.5)$ & $238(92.6)$ & $207(94.1)$ & $103(97.2)$ & & \\
\hline \multicolumn{7}{|l|}{ ROSC$^{*}:$} \\
\hline Yes & $478(43.9)$ & $257(44.9)$ & $220(41.2)$ & $106(34.6)$ & \multirow[t]{2}{*}{0.02} & 0.007 \\
\hline No & $610(56.1)$ & $315(55.1)$ & $314(58.8)$ & $200(65.4)$ & & \\
\hline $\begin{array}{l}\text { Overall } \\
\text { mortality*: }\end{array}$ & $907(65.5)$ & $460(64.2)$ & $489(69.0)$ & $385(78.4)$ & $<0.001$ & $<0.001$ \\
\hline
\end{tabular}

Data are presented as number and percentages unless otherwise indicated. ED - emergency department, ICCU - intensive coronary care unit, NA - not applicable, OHCA - out-of-hospital cardiac arrest, ROSC - return of spontaneous circulation, VF - ventricular fibrillation, $V T$-ventricular tachycardia, ${ }^{*}$ overall mortality - dead on arrival + unsuccessful resuscitation; ${ }^{*}$ data presented according to Utstein criteria. 
Table III. Logistic regression analysis for prediction of the cardiac cause of out-of-hospital cardiac arrest, shockable rhythm and return of spontaneous circulation

\begin{tabular}{|c|c|c|c|c|c|c|}
\hline \multirow[t]{2}{*}{ Variable } & \multicolumn{2}{|c|}{ Univariable } & \multicolumn{2}{|c|}{ Multivariable (enter) } & \multicolumn{2}{|c|}{ Multivariable (forward) } \\
\hline & OR $(95 \% \mathrm{Cl})$ & $P$-value & OR $(95 \% \mathrm{Cl})$ & $P$-value & OR $(95 \% \mathrm{Cl})$ & $P$-value \\
\hline \multicolumn{7}{|c|}{ Prediction of the cardiac cause of out-of-hospital cardiac arrest: } \\
\hline Age; per each group & $1.29(1.19-1.39)$ & $<0.001$ & $1.33(1.23-1.44)$ & $<0.001$ & $1.32(1.22-1.43)$ & $<0.001$ \\
\hline Sex; male vs. female & $1.09(0.92-1.29)$ & 0.31 & $1.30(1.09-1.55)$ & 0.003 & $1.30(1.09-1.55)$ & 0.01 \\
\hline Area; urban vs. rural & $1.06(0.89-1.25)$ & 0.50 & $1.14(0.95-1.37)$ & 0.156 & \multicolumn{2}{|c|}{ Not included } \\
\hline Location; home vs. other & $1.07(0.89-1.28)$ & 0.48 & $0.79(0.61-1.02)$ & 0.08 & \multicolumn{2}{|c|}{ Not included } \\
\hline Eyewitness; family vs. other & $1.28(1.06-1.54)$ & 0.009 & $1.50(1.16-1.93)$ & 0.002 & $1.27(1.04-1.53)$ & 0.02 \\
\hline Time to arrival; per $1 \mathrm{~min}$ & $0.99(0.99-1.01)$ & 0.87 & $1.00(0.99-1.010$ & 0.89 & \multicolumn{2}{|c|}{ Not included } \\
\hline Witnesses; yes vs. no & $1.32(1.11-1.57)$ & 0.001 & $1.41(1.18-1.69)$ & 0.001 & $1.40(1.17-1.67)$ & $<0.001$ \\
\hline \multicolumn{7}{|l|}{ Prediction of shockable rhythm: } \\
\hline Age; per each group & $0.73(0.66-0.82)$ & $<0.001$ & $0.8(0.71-0.9)$ & $<0.001$ & $0.8(0.71-0.9)$ & 0.01 \\
\hline Sex; male vs. female & $1.72(1.35-2.18)$ & $<0.001$ & $1.46(1.13-1.87)$ & 0.004 & $1.46(1.13-1.87)$ & 0.01 \\
\hline Area; urban vs. rural & $1.64(1.33-2.03)$ & $<0.001$ & $1.42(1.11-1.82)$ & 0.005 & $1.42(1.11-1.82)$ & 0.01 \\
\hline Location; home vs. other & $0.48(0.38-0.61)$ & $<0.001$ & $0.6(0.44-0.83)$ & 0.002 & $0.61(0.48-0.77)$ & $<0.001$ \\
\hline Eyewitness; family vs. other & $0.56(0.45-0.71)$ & $<0.001$ & $1.02(0.74-1.41)$ & 0.91 & \multicolumn{2}{|c|}{ Not included } \\
\hline Time to arrival; per $1 \mathrm{~min}$ & $0.97(0.95-0.99)$ & 0.001 & $0.98(0.96-0.99)$ & 0.01 & $0.98(0.96-0.995)$ & 0.01 \\
\hline Witnesses; yes vs. no & $1.56(1.25-1.94)$ & 0.001 & $1.52(1.21-1.91)$ & $<0.001$ & $1.52(1.21-1.9)$ & 0.01 \\
\hline \multicolumn{7}{|c|}{ Prediction of return of spontaneous circulation: } \\
\hline Age; per each group & $0.90(0.84-0.97)$ & 0.01 & $0.95(0.87-1.04)$ & 0.25 & \multicolumn{2}{|c|}{ Not included } \\
\hline Sex; male vs. female & $0.96(0.81-1.14)$ & 0.64 & $0.80(0.67-0.94)$ & 0.02 & $0.83(0.69-0.99)$ & 0.04 \\
\hline Area; urban vs. rural & $2.06(1.74-2.43)$ & $<0.001$ & $1.58(1.31-1.92)$ & $<0.001$ & $1.57(1.30-1.91)$ & $<0.001$ \\
\hline Location; home vs. other & $0.56(0.47-0.67)$ & $<0.001$ & $0.99(0.76-1.29)$ & 0.93 & \multicolumn{2}{|c|}{ Not included } \\
\hline Eyewitness; family vs. other & $0.49(0.41-0.59)$ & $<0.001$ & $0.56(0.43-0.73)$ & $<0.001$ & $0.53(0.43-0.64)$ & $<0.001$ \\
\hline Time to arrival; per $1 \mathrm{~min}$ & $0.95(0.94-0.96)$ & $<0.001$ & $0.97(0.77-1.29)$ & $<0.001$ & $0.97(0.96-0.99)$ & $<0.001$ \\
\hline Witnesses; yes vs. no & $1.3(1.09-1.54)$ & 0.01 & $1.17(0.97-1.41)$ & 0.1 & \multicolumn{2}{|c|}{ Not included } \\
\hline $\begin{array}{l}\text { Cause of OHCA; cardiac } \\
\text { vs. other }\end{array}$ & $1.42(1.21-1.66)$ & $<0.001$ & $1.28(1.07-1.52)$ & 0.006 & $1.27(1.07-1.51)$ & 0.007 \\
\hline $\begin{array}{l}\text { Shockable rhythm; yes } \\
\text { vs. no }\end{array}$ & $4.63(3.66-5.85)$ & $<0.001$ & $3.99(3.12-5.10)$ & $<0.001$ & $4.10(3.21-5.23)$ & $<0.001$ \\
\hline
\end{tabular}

Data are presented as odds ratios and 95\% confidence intervals. AUC - area under the curve, OHCA - out-of-hospital cardiac arrest.

The current study addresses issues of equal access to treatment interventions related to OHCA among younger and older patients. The most important finding of this study is that male sex, rural area and home location strongly contributed to the ineffectiveness of resuscitation and more frequent death declared upon arrival, resulting in a poor short- and long-term prognosis in the elderly patients following OHCA. The presence of shockable initial rhythm, urban area and family-witnessed OHCA were the strongest predictors of survival. Similar reports on multiple predictors of mortality in OHCA patients stratified by age are scarce. Our four age group approach was similar to that reported by Tsunoyama et al. [14] and Deasy et al. [15]; however, they focused on dispatcher-guided CPR [14] or the studies were conducted in a setting other than Poland (i.e. Australia) [15]. Patient registries provide a wealth of clinical information. Results from meta-analysis of registry-based studies can be applied in clinical practice for diagnosing and treating diseases. Likewise, OHCA databases both on a European and national scale have been used for a number 


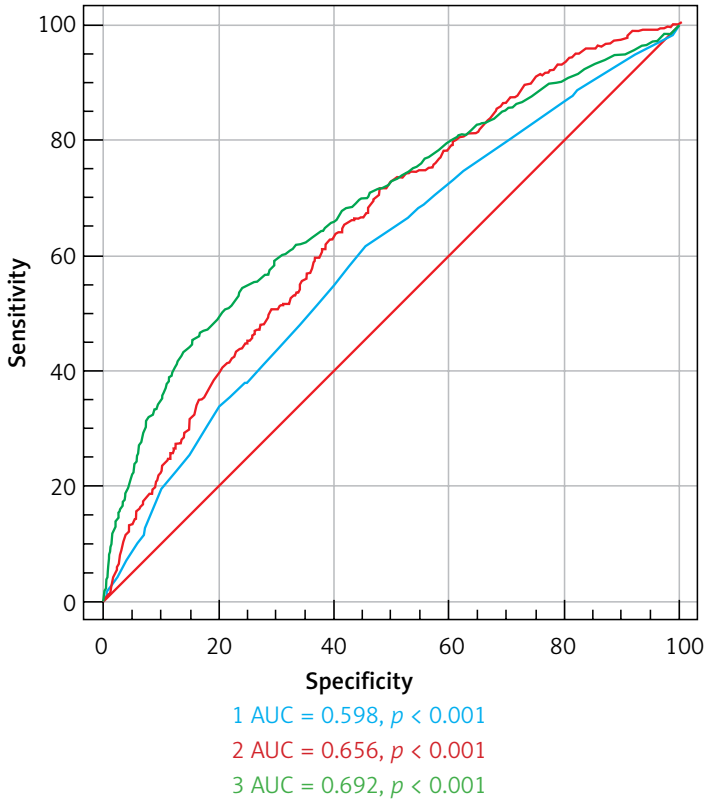

Figure 3. Receiver operating characteristic curves for multivariable logistic regression model for (1) cardiac cause of out-of-hospital cardiac arrest, (2) initial shockable rhythm in out-of-hospital cardiac arrest, (3) return of spontaneous circulation. AUC, area under the curve

of years [18-20]. In Poland, registry-based studies on OHCA are also carried out, although there is no national registry of OHCA in the country as yet [21-23].

In the present study we analyzed the outcome of 2,500 patients who received CPR in a small district in one of the EU countries based on a regional OHCA registry. The fundamental question, extremely important from the viewpoint of both theory and practice, is which factors affect the success of resuscitation and whether they are equally considered in the whole population, especially in the elderly. In this report both univariate and multivariable regression analyses demonstrated that age was significantly associated with an OHCA of cardiac etiology and the presence of a shockable initial rhythm. These results are consistent with data obtained in large European studies. Wiel et al. in a large sample of 8,694 patients divided into those less than 65 and over 65 years old found a lower ROSC rate in relation to age [18]. In the Polish population, Nadolny et al. compared the

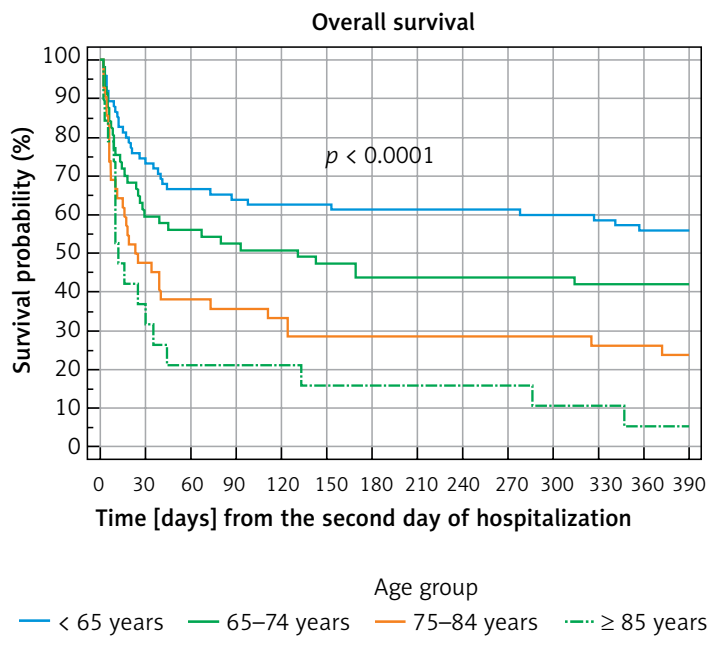

Figure 4. Probability of survival after out-of-hospital cardiac arrest depending on age groups

OHCA occurrence in younger and older patients living in various locations throughout the District of Silesia. A total of 1,603 patients with a mean age of 65.7 years who experienced OHCA were included in the study. The largest number of OHCA events was observed in patients over 65 years of age [21]. However, no further analysis of individual age groups and prehospital care is available. No comparative report on prehospital care in patients divided by age was found in the Polish literature. Time to EMS arrival is a crucial parameter in the quality assessment of the management of patients with OHCA across different age ranges. In the present report, both univariate and multivariable regression analysis showed that shorter time to arrival was associated with an OHCA of cardiac etiology and the presence of a shockable initial rhythm. In the study of Winther-Jensen et al. in a group of 2,509 patients divided into those below and over 80 years of age there were no differences in time to arrival and its effect on survival [19]. Bystanders and family members who recognize an impending cardiac arrest and call an ambulance play an important role in the chain of survival. In this survey, both univariate and multivariable regression analysis showed that family presence at the scene had a weaker relationship with a cardiac cause of OHCA and the occurrence of shockable initial rhythms. In contrast, bystander presence

Table IV. Survival proportions and hazard ratios based on Kaplan-Meier estimates

\begin{tabular}{|lccccc|}
\hline Survival time & \multicolumn{5}{c|}{ Survival proportion (standard error) (\%) } \\
\cline { 2 - 6 } & Total & $<65$ years & $65-74$ years & $\mathbf{7 5 - 8 4}$ years & $\geq 85$ years \\
\hline 30 days & $59.8(3.5)$ & $73.3(5.1)$ & $59.6(6.5)$ & $47.6(7.7)$ & $31.6(10.7)$ \\
\hline 365 days & $40.4(3.5)$ & $56.0(5.7)$ & $42.1(6.5)$ & $26.2(6.8)$ & $5.3(5.1)$ \\
\hline $\begin{array}{l}\text { Hazard ratio }(95 \% \mathrm{Cl}) \text { for the } \\
\text { group under 65 years old }\end{array}$ & 1 & $1.57(1.05-2.36)$ & $2.37(1.46-3.85)$ & $3.62(1.72-7.62)$ \\
\hline
\end{tabular}


had a positive effect on both variables. It may be speculated that family members are familiar with the chief complaints of patients, especially the elderly ones and react differently than bystanders. In a systematic review by van de Glind et al. multivariable regression analysis of data reported in 10 papers showed that witnessed OHCA was a significant predictor of survival after ROSC [8]. Similarly, Requena-Morales et al. in an analysis of 422 OHCA cases occurring in the district of Alicante (similar to Świętokrzyskie District in terms of the number of inhabitants) confirmed the significant role of witnesses during OHCA and their effect on mortality [20]. The present findings do suggest that there is a relationship between time to arrival at the scene and the presence of shockable initial rhythms. In univariate and multivariable regression analysis the shorter the time to arrival is, the more probable is shockable initial rhythm. According to Gräsner et al. only $20-25 \%$ of patients have an initial recorded rhythm indicating ventricular fibrillation. Therefore, it may be speculated that if time to arrival at the scene was shorter, the chance of first defibrillation would be higher [16]. We confirmed the relationship between shockable initial rhythm and patient age, gender, location of the incident (urban/rural area), site of the incident (home/other) and the reporting subject, time to arrival at the scene and witnessed arrest. Gach et al. carried out a similar survey in Bielsko-Biala District including 272 OHCA cases and reported that failure to initiate chest compression by lay bystanders and non-shockable initial rhythm were the independent predictors of prehospital death associated with long-lasting hypoxia [21]. Nadolny et al. in a study of 1,603 patients with OHCA in Katowice District divided into those below and over 65 years of age demonstrated that early chest compression, age, early defibrillation and intubation with oxygen therapy, and ECG monitoring were the independent factors for better prognosis [22]. In the current study the Kaplan-Meier survival curves for patients categorized by age demonstrated the lowest survival rate for the oldest patients and highest among the youngest subjects. Analysis of survival proportions in the consecutive age groups at 30 days and 365 days after the OHCA showed the lowest survival index among the oldest patients and highest among the youngest subjects. These results reflect those of Segal et al., who also found the lowest survival in the oldest patients among 18,249 OHCA subjects [23]. The presence of multiple comorbidities in the elderly may have an impact on ROSC following OHCA, accounting for significantly worse outcomes in this age group. Nadolny et al. published the results of multidirectional analysis of prehospital care based on the POL-OHCA registry
[24]. The investigators analyzed 26,783 CPR attempts made in the whole of Poland in 2018. The results of our analysis, which was conducted for the 2013-2017 study period taking into account younger and older age groups within only one district, may supplement the information obtained from the national registry. This retrospective study seems to provide evidence that age is not an appropriate factor for evaluation of prehospital care in patients experiencing an OHCA. The roles of OHCA witnesses, CPR attempts, availability and use of an automated external defibrillator (AED), and medical emergency dispatchers appear to be of high clinical importance. In our district the availability of AED is very low. There are only 10 devices, which are placed in several offices, petrol stations and public buildings [25]. There has already been an attempt to establish a CPR-AED program to be implemented in lower and upper secondary schools [26]. Hopefully, all these actions will improve medical care for patients with OHCA.

In Swietokrzyskie District ECMO-facilitated resuscitation is not used in OHCA patients because of the lack of appropriate ambulance equipment. In Poland, ECMO in OHCA patients is tested as part of the pioneer Out-of-Hospital Cardiac Arrest Program implemented in Wielkopolskie District [16]. Recent evidence shows significantly improved survival in patients receiving ECMO-assisted cardiopulmonary resuscitation [27]. The present study appears to demonstrate that the effectiveness of CPR in the elderly (shockable rhythm and cardiac etiology decrease with age) is associated with performance of high quality cardiopulmonary resuscitation and active participation of the bystander in CPR (an especially recommended procedure for the elderly). Wide dissemination of AEDs throughout a community (for instance elderly care homes, reading rooms) with legible and understandable information on how to call an ambulance for a medical emergency (wall posters in public places, educational centers, places of worship) and first aid courses for senior citizens may contribute to better results. It would be valuable for medical professionals to participate in courses explaining the differences in providing first aid to OHCA patients with pacemakers and cardiac defibrillators. The new subcutaneous implantable cardioverter-defibrillator systems may be a promising alternative for the elderly [28]. Dissemination of accurate information by mass media (newspapers, radio, television) may increase the awareness of OHCA among bystanders. Primary care physicians can significantly contribute to education of patients (summary information booklets, chatting/talking with patients) on OHCA and CPR. Education in rural areas can be implemented in churches. Educational campaigns carried out by 
the Polish Cardiac Society are a good source of information about cardiac arrest in public locations with nearby bystanders. A separate issue in the management of patients after OHCA is neuroprotection after cardiac arrest. As presented in the work of Arrich et al. in a meta-analysis of 7 studies involving 2,369 patients, early initiation of therapeutic hypothermia is important in improving the prognosis and reducing the risk of damage to the central nervous system after OHCA [29]. Also, Fröhlich et al. in a review of etiological factors and factors improving prognosis after in-hospital and out-of-hospital cardiac arrest highlighted the important role of neuroprotection with therapeutic hypothermia [30]. The study, where cases of neuroprotection in OHCA were assessed, come from the area of the Świętokrzyskie Voivodeship and the authors' center. Ciuraszkiewicz et al. describe the first experiences in implementing the method of mild therapeutic hypothermia after OHCA [31].

In conclusion, out of numerous factors influencing the efficacy of resuscitation the presence of shockable initial rhythm and urban location of an OHCA were the strongest predictors of return of spontaneous circulation. Survival at 30 and 365 days following OHCA decreased in older patients. Further work should be considered to establish special procedures for older patients with OHCA in order to eliminate age differences in prehospital care. Both older and younger individuals have equal access to prehospital critical care for OHCA. Survival among older patients with OHCA is worse than in younger subjects, which is a result of both lower efficacy of resuscitation and more frequent death declared upon arrival.

\section{Conflict of interest}

The authors declare no conflict of interest.

\section{References}

1. Kouwenhoven WB, Jude JR, Knickerbocker GG. Closedchest cardiac massage. JAMA 1960; 173: 1064-7.

2. Berdowski J, Berg RA, Tijssen JGP. et al. Global incidences of out-of-hospital cardiac arrest and survival rates: systematic review of 67 prospective studies. Resuscitation 2010; 81: 1479-87.

3. Clegg GR, Lyon RM, James S, et al. Dispatch-assisted CPR: where are the hold-ups during calls to emergency dispatchers? A preliminary analysis of caller-dispatcher interactions during out-of-hospital cardiac arrest using a novel call transcription technique. Resuscitation 2014; 85: 49-52.

4. Monsieurs KG, Nolan JP, Bossaert LL, et al. European Resuscitation Council Guidelines for Resuscitation 2015. Resuscitation 2015; 95: 1-80.

5. Statistics Poland. https://stat.gov.pl/en/topics/statistical-yearbooks/statistical-yearbooks/demographic-yearbook-of-poland-2018,3,12.html. Accessed March 1, 2020.

6. Wojtyniak B, Goryński P. Health situation of the Polish population and its determinants - synthesis. National
Institute of Public Health - National Institute of Hygiene. Warsaw 2018; 492.

7. World Health Organization. The European Health Report 2012. Charting the Way to Well-Being. WHO; Copenhagen 2013.

8. Van de Glind EM, van Munster BC, van de Wetering FT, et al. Pre-arrest predictors of survival after resuscitation from out-of-hospital cardiac arrest in the erlderly: a systematic review. BMC Geriatr 2013; 13: 1-10.

9. Bledowski P, Mossakowska M, Chudek J, et al. Medical, psychological and socioeconomic aspects of aging in Poland: assumptions and objectives of the PolSenior project. Exp Gerontol 2011; 46: 1003-9.

10. https://stat.gov.pl (accessed May 10, 2018).

11. Piotrowska-Piątek A, Górski D, Szynocha O. Demographic prognosis for Świętokrzyskei Voivodship for 2050. In: Hrynkiewicz J, Potrykowska A. Demographic situation of Świętokrzyskie Voivodoship as a challenge for social and economic policy. Rządowa Rada Ludnościowa, Warsaw 2017; 58-69.

12. Kowalik RJ, Fojt A, Ozierański K, et al. Results of targeted temperature management of patients after sudden out-of-hospital cardiac arrest: a comparison between intensive general and cardiac care units. Kardiol Pol 2020; 78: 30-6.

13. Sielski J, Kaziród-Wolski K, Siudak Z. Out of hospital cardiac arrest: data from the National Registry of Invasive Cardiology Procedures (ORPKI) in a longterm survival analysis of patients with acute coronary syndromes in a Polish region. Kardiol Pol 2020; 78: 412-9.

14. Tsunoyama T, Nakahara S, Yoshida M, et al. Effectiveness of dispatcher training in increasing bystander chest compression for out-of-hospital cardiac arrest patients in Japan. Acute Med Surg 2017; 4: 439-45.

15. Deasy C, Bray JE, Smith K, et al. Out-of-hospital cardiac arrest in the older age groups in Melbourne, Australia. Resuscitation 2011; 82: 398-403.

16. Sip M, Puślecki M, Kłosiewicz T, et al. A concept of the pioneer regional Out-of-Hospital Cardiac Arrest Program development to improve the outcomes of patients with out-of-hospital cardiac arrest. Kardiol Pol 2020; 78: 875-81.

17. MedCalc Statistical Software. Version 19.1. MedCalc Software; 2019. https://www.medcalc.org. Accessed September 15, 2019.

18. Wiel E, di Pompeo C, Segal N, et al. Age discrimination in out-of-hospital cardiac arrest care: a case-control study. Eur J Cardiovasc Nurs 2018; 17: 505-12.

19. Winther-Jensen M, Kjaergaard J, Hassager C, et al. Resuscitation and post resuscitation care of the very old after out-of-hospital cardiac arrest is worthwhile. Int J Cardiol 2015; 201: 616-23.

20. Requena-Morales R, Palazón-Bru A, Rizo-Baeza MM, et al. Mortality after out-of-hospital cardiac arrest in a Spanish Region. PLoS One 2017; 12: e0175818.

21. Gach D, Nowak JU, Krzych LJ. Epidemiology of out-of-hospital cardiac arrest in Bielsko-Biała district: a 12-month analysis. Kardiol Pol 2016; 74: 1180-7.

22. Nadolny K, Gotlib J, Panczyk M, et al. The epidemiology of sudden cardiac arrest in prehospital care in the area of Silesian voivodship. Wiad Lek 2018; 71: 193-200.

23. Segal N, di Pompeo C, Escutnaire J, et al. Evolution of survival in cardiac arrest with age in elderly patients: is resuscitation a dead end? J Emerg Med 2018; 54: 295-301.

24. Nadolny K, Zyśko D, Obremska M, et al. Analysis of out-of-hospital cardiac arrest in Poland in a 1-year period: data from the POL-OHCA registry. Kardiol Pol 2020; 78: 404-11. 
25. http://www.ratujzsercem.pl/Defibrylacja/LokalizacjaAED/MiastazAED.aspx (accessed July 21, 2020).

26. Sielski J, Jóźwiak M, Jóźwiak MA. AED Network in Świętokrzyskie Voivodship's high schools as an element of out-of-hospital treatment. Poster session at: Polish Preventive Cardiology Sessions 2017; Nov 23.

27. Bartos JA, Grunau B, Carlson C, et al. Improved survival with extracorporeal cardiopulmonary resuscitation despite progressive metabolic derangement associated with prolonged resuscitation. Circulation 2020; 141: 877-86.

28. Ammannaya G. Implantable cardioverter defibrillators the past, present and future. Arch Med Sci Atheroscler Dis 2020; 5: 163-70.

29. Arrich J, Holzer M, Havel C, et al. Pre-hospital versus in-hospital initiation of cooling for survival and neuroprotection after out-of-hospital cardiac arrest. Cochrane Database Syst Rev 2016; 3: CD010570.

30. Fröhlich GM, Lyon RM, Sasson C, et al. Out-of-hospital cardiac arrest - optimal management. Curr Cardiol Rev 2013; 9: 316-24.

31. Ciuraszkiewicz K, Janion-Sadowska A, Sielski J. Mild therapeutic hypothermia after cardiac arrest due to acute coronary syndrome - experience from the implementation of the method. Folia Cardiol 2014; 9: 327-36. 